\title{
Retraction Note: Reliability of variable slope system and human motion image detection based on Markov chain
}

\author{
Liu Xuewei ${ }^{1} \cdot$ Bu Te $^{2}$
}

Published online: 2 December 2021

C) Saudi Society for Geosciences 2021

Retraction Note: Arabian Journal of Geosciences (2021) 14: 978

https://doi.org/10.1007/s12517-021-07244-7

The Editor-in-Chief and the Publisher have retracted this article because the content of this article is nonsensical. The peer review process was not carried out in accordance with the Publisher's peer review policy. Author Bu Te disagrees with this retraction. The Publisher has not been able to obtain a current email address for author Liu Xuewei.

The original article can be found online at https://doi.org/10.1007/ s12517-021-07244-7

$\mathrm{Bu} \mathrm{Te}$

liuxuewei199712@163.com

1 Wenzhou University, Wenzhou 325035, China

2 Hunan Normal University, Changsha 410000, China 